\title{
Determination of Early Neurological Outcome by ASIA score following Delayed Anterior Decompression and Stabilization of Lower Cervical Spine Injury
}

\author{
Mohammed Ashraful Haque', SK Sader Hossain², Md. Mahfuzur Rahman³, \\ Md. Rafiqul Islam ${ }^{4}$, Sadika Kadir ${ }^{5}$, Golam Sagir ${ }^{6}$, Md. Aminul Hasanat ${ }^{7}$
}

\begin{abstract}
${ }^{1}$ Assistant Professor, Department of Neurosurgery, National Institute of Neurosciences \& Hospital, Dhaka, Bangladesh; ${ }^{2}$ Professor \& Head, Department of Neurosurgery, National Institute of Neurosciences \& Hospital, Dhaka, Bangladesh $;^{3}$ Assistant Professor, Department of Neurosurgery, National Institute of Neurosciences \& Hospital, Dhaka, Bangladesh; ${ }^{4}$ Assistant Professor, Department of Neurosurgery, National Institute of Neurosciences \& Hospital, Dhaka, Bangladesh;

${ }^{5}$ Assistant Professor, Department of Paediatrics, ZH Sikder Women Medical College \& Hospital, Dhaka,

Bangladesh; ${ }^{6}$ Consultant, Department of Neurology, National Institute of Neurosciences \& Hospital, Dhaka, Bangladesh; ${ }^{7}$ Assistant Professor, Department of Anaesthesiology, National institute of Neurosciences \& Hospital, Dhaka, Bangladesh
\end{abstract}

[Received: 2 March 2018; Revised on: 10 April 2018; Accepted on: 22 May 2018; Published on: 1 July 2018]

\begin{abstract}
Background: Surgical management of lower cervical spine injury is a very important issue among these patients. Objective: The purpose of the present study was todetermine the early neurological outcome of delayed anterior decompression and stabilization of lower cervical spine injury. Methodology: This cross sectional study was carried out in the Department of Neurosurgery at Dhaka Medical College and Hospital, Dhaka, Bangladesh within the period of January 2010 to July 2011 for a period of one year and 6 months. Neurological outcome following anterior decompression and stabilization of lower cervical spine injury was observe. Patients presented with lower cervical spine injury were included in this prospective study. Quantification of neurologic deficit in lower cervical spine injury patients were carried out by following The American Spinal Injury Association (ASIA) impairment scale. Early neurological outcome was also assessed after operation by using ASIA impairment scale in the follow up period at one, three and six months interval. Result: A total of 31 patients were included in this study. Based on the ASIA impairment scale, preoperatively, $6.45 \%$ of the injuries were grade A, $16.13 \%$ of the injuries were Grade B, $16.13 \%$ of the injuries were Grade C and $35.48 \%$ of the injuries were Grade D. early post-operative complications include dysphagia in $35.48 \%$ cases, donor site infection in $9.67 \%$ cases, CSF leak in $3.22 \%$; catheter related urinary tract infection $9.67 \%$ and bed sore occurred in $6.45 \%$ cases. Conclusion: In conclusion significant neurological recovery can be expected following delayed anterior decompression and stabilization of lower cervical spine in lower cervical spine injury patient. [Journal of National Institute of Neurosciences Bangladesh, 2018;4(2): 82-86]
\end{abstract}

Keywords: Socio-demographic characteristics; lower; cervical spine; injury

Correspondence: Dr. Mohammed Ashraful Haque, Assistant Professor, Department of Neurosurgery, National Institute of Neurosciences \& Hospital, Sher-E-Bangla Nagar, Agargaon, Dhaka-1207, Bangladesh; Email: dr.ashraful2002@gmail.com;Cell no.: $+8801715864313$

Conflict of interest: There is no conflict of interest relevant to this paper to disclose.

Funding agency: This research project was not funded by any group or any institution.

Contribution to authors: Haque MA, Rahman MM, Sagir G, Hasanat MA, data collection, protocol preparation, report writing, revised; SK Sader Hossain, supervisor; Islam R, Hossain SS, Ashraful Haque, data collection; Rahman MM, data collection; Golam Kabir, Sadika Kadir Image analysis

How to cite this article: Haque MA, Hossain SkS, Rahman MM, Islam MR, Kadir S, Sagir G, Hasanat MA. Determination of Early Neurological Outcome by ASIA score following Delayed Anterior Decompression and Stabilization of Lower Cervical Spine Injury. J Natl InstNeurosci Bangladesh, 2018;4(2): 82-86

Copyright: (02018. Haque et al. Published by Journal of National Institute of Neurosciences Bangladesh. This article is published under the Creative Commons CC BY-NC License (https://creativecommons.org/licenses/by-nc/4.0/). This license permits use, distribution and reproduction in any medium, provided the original work is properly cited, and is not used for commercial purposes.

\section{Introduction}

Cervical spinal trauma complicated by injury to the spinal cord is an important cause of morbidity and mortality particularly among the teen agers and young adults ${ }^{1}$. Current advance in the safety and efficacy of spinal cord surgical decompressive procedures offers significant potential for repairing some of the neurological damage caused by injuries to the spine ${ }^{2}$. 
Immediate spinal column stabilization and spinal cord decompression, significantly improved neurologic outcome, decrease hospitalization time and postoperative complications in patients with cervical spinal cord injuries $^{3}$.

In a study with traumatic, incomplete cervical spinal cord injuries neurologic recovery was not related to the some factors likegender, race, type of fracture, or mechanism of injury ${ }^{4}$. Neurologic recovery was not related to the interventions of high dose methylprednisolone administration, early definitive surgery, early anterior decompression for burst fractures or disk herniation or decompression of stenotic canals without fracture ${ }^{5}$. Actually the most important prognostic variable relating to neurologic recovery in a patient with acute cervical spinal cord injury is the completeness of the lesion ${ }^{6}$.

Controversy exists as to the ideal timing and the benefits derived from undergoing acute decompressive surgery after acute spinal cord injury ${ }^{7}$. It has been recommended early operative decompression of neural elements. Admissionstatus correlated significantly with spinal canal narrowing but not with vertebral body displacement. In Bangladesh, road communication is underdeveloped, facilities of transportation of an injured patient is poor, there is scarcity of trained first aid personnel and awareness of the necessity for swift and judicious management, majority of injured patients arrive too late at organized centers that possesses specialized equipment and trained doctors and paramedics. Moreover, imaging facilities are inadequate and costly. As a result, proper medications and surgical managements are also delayed in these patients. Considering these facts, this present study was undertaken todetermine the early neurological outcome of delayed anterior decompression and stabilization of lower cervical spine injury.

\section{Methodology}

This was a prospective cohort study and was carried out in the Department of Neurosurgery at Dhaka Medical College Hospital, Dhaka, Bangladesh from January, 2010 to June, 2011for a period of one year and 6 months. All patients with lower cervical spine injury due to traumatic event, managed surgically by delayed (after 72 hours) anterior decompression and stabilization were included in this study.Nonprobability sampling from consecutive cases diagnosed clinico-radiologically and finally included on operative notes.Other associated surgical or orthopedic injury that interferes with the neurological examination, head or neurological injury that precluded surgery or neurological assessment, concurrent illness that would interfere with surgery or post-operative neurological status, patient who denied to be included and patient who was neurologically intact (ASIA grade E) were excluded from this study.The patients available for the study were examined and findings are documented as per questionnaire; the relevant investigations were then performed.The patients who underwent operation were re-examined and operative findings were documented.Post-operative patients were followed up the date of operation up to discharge from the hospital.Neuro-radilogical images were recorded.Operative findings were recorded.Most cases were admitted late and operations were carried out as late 15 (fifteen) days to 32 (thirty two) days after injury.During the period of preceding surgery the patients were managed conservatively with Cervical Collar, Gardner-Well tong traction according to need by the clinical condition of the patient.All the patients were investigated by radiograph, MRI and CT scan of cervical spine accordingly. The indications of surgery were persistent cervical spinal cord compression and/or instability of cervical spine.The goal of surgery was to relieve persistent compression of the spinal cord, restore spinal stability and to allow mobilization of the patient.The collected data were edited, compiled and statistical analysis were done using computer based software SPSS program. The data will be presented in tables and graphs as needed.Prior to the commencement of this study, the research protocol was approved by the thesis committee (local ethical committee).

\section{Results}

A total number of 42 patients were operated for lower cervical injury during the study period. Among them, 31 patients were meeting the inclusion criteria of this study. So, the sample size is 31 . Measures of central tendencies were, Mean age with SD was $32.9 \pm 10.35$ years. Minimum age of the patient was 18 years and maximum age of the patient was 57 years (Table 1).

Table 1: Age Distribution of the Patients

\begin{tabular}{lcc}
\hline Age Group & Frequency & Percentage \\
\hline 11 to 30 Years & 12 & 38.7 \\
31 to 50 Years & 16 & 51.6 \\
51 to 60 Years & 3 & 9.7 \\
Total & 31 & $\mathbf{1 0 0 . 0}$ \\
\hline
\end{tabular}

In this study early post-operative complications include dysphagia in $35.48 \%$ cases, donor site infection in 9.67\% cases, CSF leak in 3.22\%; catheter related 
urinary tract infection $9.67 \%$ and bed sore occurred in $6.45 \%$ cases(Table 2).

Table 2: Early Postoperative complications (within one week of operation)

\begin{tabular}{lcc}
\hline Complication & Frequency & Percentage \\
\hline Dysphagia & 11 & 35.48 \\
CSF Leak & 1 & 3.22 \\
Catheter related UTI & 3 & 9.67 \\
Infection(DonorSite) & 3 & 9.67 \\
Bed sore & 2 & 6.45 \\
\hline
\end{tabular}

UTI=urinary tractinfection; Multiple Response analysis

The time interval from surgical decompression to discharge varied from 12 to 36days, with an average of Mean $\pm \mathrm{SD}=24.8 \pm 5.07$ days (Table 3).

Table3: Time interval from surgery to discharge from the hospital

\begin{tabular}{lcc}
\hline Duration & Frequency & Percentage \\
\hline 10 to 14 Days & 1 & 3.22 \\
15 to 19 Days & 3 & 9.68 \\
20 to 24 Days & 11 & 35.48 \\
25 to 29 Days & 13 & 41.93 \\
30 to 34 Days & 2 & 6.45 \\
35 to 39 Days & 1 & 3.22 \\
Total & $\mathbf{3 1}$ & $\mathbf{1 0 0 . 0}$ \\
\hline
\end{tabular}

On discharge Mean ASIA Score was (Mean \pm SD) $3.7 \pm 0.82$. Among 31 patients $15(48.38 \%)$ patients improved at least one ASIA Grade at the time of discharge (Table 4).

Table4:Neurological status on discharge on the basis of ASIA Grade (ASIA grades leveled as 1 to 5 corresponding to A-E respectively)

\begin{tabular}{lcccc}
\hline $\begin{array}{c}\text { ASIA } \\
\text { Grade }\end{array}$ & $\begin{array}{c}\text { No. of pt. } \\
\text { on admission }\end{array}$ & $\begin{array}{c}\text { No. of pt. on } \\
\text { discharge }\end{array}$ & $\begin{array}{c}\text { No. of pt. } \\
\text { improved }\end{array}$ & $\begin{array}{c}\text { \% of pts. } \\
\text { Improved }\end{array}$ \\
\hline A(1) & 2 & 2 & 0 & \\
B (2) & 5 & 3 & 1 to C, I to D. & \\
C(3) & 13 & 9 & 4 toD, ltoE & 48.38 \\
D(4) & 11 & 8 & 8 toE & \\
E (5) & Not included & 9 & & \\
Total & $\mathbf{3 1}$ & $\mathbf{3 1}$ & $\mathbf{1 5}$ & \\
\hline
\end{tabular}

In this study ASIA grade A(1) was reported in 2 cases during admission and discharge. ASIA grade $\mathrm{B}(2)$ was found in 5 and 3 cases in admission and discharge. ASIA grade C(3) was measured in 13 and 9 cases at the time of admission and discharge. ASIA grade $\mathrm{D}(4)$ was found in 11 and 8 cases in admission and discharge. With Paired t test, $\mathrm{t}=-4.96 \mathrm{df}=29$. The two-tailed $\mathrm{P}$ value is less than 0.001 . Change in neurological status is statistically significant (Table 6).

Table5:Comparison of preoperative and postoperative (at the time of discharge) ASIA Score (ASIA grades leveled as 1 to 5 corresponding to A-E respectively)

\begin{tabular}{lcc}
\hline ASIA & \multicolumn{2}{c}{ Number of Patients } \\
\cline { 2 - 3 } Grade & Admission & Discharge \\
\hline A(l) & 2 & 2 \\
B $(2)$ & 5 & 3 \\
C(3) & 13 & 9 \\
D $(4)$ & 11 & 8 \\
E $(5)$ & Not included & 9 \\
Total & $\mathbf{3 1}$ & $\mathbf{3 1}$ \\
\hline
\end{tabular}

\section{Discussion}

Currently there are many different conservative and operative procedures are used for the treatment of cervical spine injuries which reflects the fact lack of a clearly superior technique ${ }^{8}$. The treatment of cervical spine fractures and dislocation is not established and therefore any well-considered procedure deserves considerations. It has been adopted delayed anterior decompression and stabilization as a single stage procedure for lower cervical spine injury, intending that this relieves pressure on the spinal cord, stabilize the spine and make the patient possible for early mobilization?.

In this current study Neurological Outcome Following Delayed Anterior Decompression and Stabilization of Lower Cervical Spine injury, 31 patients with lower cervical spinal injury were included. All were studied prospectively. All these cases were operated upon in the Neurosurgery Department, Dhaka Medical College Hospital, Dhaka, Bangladesh. The studies were carried out using data prospectively.

In this series, minimum age of the injured patient was 18 years and maximum age of the injured patient was 57 years. $67.7 \%$ of these patients were under 40 years of age and remaining $32.3 \%$ were over 40 years of age. $29.0 \%$ injured patients were between the age of 21 to 30 years and least frequently encountered age group is 51 to 60 years $(9.7 \%)$. Mean \pm SD age was $32.9 \pm 10.35$ years at the time of accident. This current series is similar to that of the annual report of 2010 by National Spinal Cord Injury Statistical Center (NSCIC), University of Alabama at Birmingham, USA. The most common age of injury was 19 years. More than a quarter of all injuries occurred between the ages of 17 
and 22 years $(25.1 \%)$, and half of all injuries occurred between the ages of 16 and 30(50.4\%), while $9.2 \%$ of all injuries occurred at age 60 or older. Mean age for all patients was 33.9 years $(\mathrm{SD}= \pm 16.4)$. Similar result was reported which was stated a mean age of $31 \pm 14$ years ${ }^{10}$. In another studies the mean age were 32.29 \pm 10.9 years $^{11}$ and $29.01 \pm 8.89$ years $^{12}$ respectively in their study. All these results give the unfortunate picture that younger and socio-economically productive age groups are the main victims of cervical spine injuries in our country as well as abroad.

In this study, all 31 patients have been done delayed anterior decompression of cervical spinal cord and autologous bone graft stabilizations with plate and screw fixation for post traumatic unstable lower cervical spine. There are many methods available for surgical decompression and stabilizations for unstable sub axial cervical spine with obvious merits to both anterior and posterior approach. The advantages of anterior decompression include the ability to achieve a more thorough and complete decompression of the cord. Moreover, the disadvantage of posterior decompression include progressive deformity and instability of the spine and possibly less recovery of neurological function due to less complete and thorough decompression of the spinal cord ${ }^{13}$. These are strongly appreciated by different studies ${ }^{14-15}$ and have been stated that anterior cervical plating has numerous potential benefits as an adjunct to anterior cervical discectomy and fusion (ACDF). It provides rigid fixation, resists graft settling, promotes higher fusion rates, allows less cumbersome external immobilization, and reduce the incidence of graft extrusions. The obvious disadvantages associated with the use of autologous bones are related to the harvesting of the graft. These drawbacks include post-operative pain often exceeding that of the primary incision, infection, nerve injury, hematoma and increased operative time. In the current series, 5(13.88\%) patients complained about donor site infection in early post-operative period, 11 patients complained about dysphagia, 1 patents complained about CSF leak which was subsided eventually bed sore occurred in $2(6.45 \%)$ patients. $8(22.2 \%)$ patients complained about the donor site pain and 6 patients complained about neck pain as a delayed post-operative complications.

The American spinal Injury association (ASIA) developed international standards for examining and reporting the severity of SCI. ASIA'S five grades of spinal cord function, $\mathrm{A}$ to $\mathrm{E}$, where $\mathrm{E}$ is normal. Individuals with the least remaining function are described by the ASIA grade A, such patients have little hope for recovery. In the present prospective study of lower cervical spinal injury, preoperative neurological status was recorded using American Spinal Injury Association (ASIA) grades as Levels 1 to 5, corresponding to Grades A to E, respectively. $11(35.48 \%)$ patients in grade D, and $13(41.93 \%)$ patients in grade $\mathrm{C}, 5(16.1 \%)$ patients in grade $\mathrm{B}$, and $2(6.45 \%)$ patients were in grade A. Average ASIA score was $\mathrm{Mcan} \pm \mathrm{SD} 3.16 \pm .93$. In this study ASIA grade A(1) was reported in 2 cases during admission and discharge. ASIA grade $\mathrm{B}(2)$ was found in 5 and 3 cases in admission and discharge. ASIA grade $\mathrm{C}(3)$ was measured in 13 and 9 cases at the time of admission and discharge. ASIA grade D(4) was found in 11 and 8 cases in admission and discharge. With paired $t$ test, $t$ $=-4.96 \mathrm{df}=29$. The two-tailed $\mathrm{P}$ value is less than 0.001 . Change in neurological status is statistically significant. Thus in this study delayed anterior decompression and stabilization played a significant role in improving neurological recovery. Here it has been assessed the result both at the time of discharge. From this current prospective study, it has been found that neurological outcome following delayed anterior decompression and stabilization of lower cervical spine injury was encouraging.

\section{Conclusion}

In this study neurological improvement following delayed anterior decompression and stabilization of lower cervical spine injury is quite satisfactory. Very few early post-operative complication occur during this surgery. Surgical intervention should be considered as soon as possible after general condition of the patient has improved and cardio-respiratory status has been stabilized.

\section{References}

1. Aebi M. Surgical treatment of upper, middle and lower cervical injuries and non-unions by anterior procedures. European spine journal. 2010;19(1):33-9

2. Brodke DS, Anderson PA, Newell DW, Grady MS, Chapman JR. Comparison of anterior and posterior approaches in cervical spinal cord injuries. Clinical Spine Surgery. 2003;16(3):229-35

3. Toh E, Nomura T, Watanabe M, Mochida J. Surgical treatment for injuries of the middle and lower cervical spine. International Orthopaedics. 2006;30(1):54-8

4. Hadley MN, Walters BC, Grabb PA, Oyesiku NM, Przybylski GJ, Resnick DK, Ryken TC. Clinical Assessment after Acute Cervical Spinal Cord Injury. Neurosurgery. 2002;50(suppl 3):S21-9

5. Koivikko MP, Myllynen P, Karjalainen M, Vornanen M, Santavirta S. Conservative and operative treatment in cervical burst fractures. Archives of orthopaedic and trauma surgery. 
2000;120(7-8):448-51

6. Lambiris E, Zouboulis P, Tyllianakis M, Panagiotopoulos E. Anterior surgery for unstable lower cervical spine injuries. Clinical orthopaedics and related research. 2003;411:61-9

7. Papadopoulos SM, Selden NR, Quint DJ, Patel N, Gillespie B, Grube S. Immediate spinal cord decompression for cervical spinal cord injury: feasibility and outcome. Journal of Trauma and Acute Care Surgery. 2002;52(2):323-32

8. O'Dowd JK. Basic principles of management for cervical spine trauma. European Spine Journal. 2010;19(1):18-22

9. Boerger TO, Limb D, Dickson RA. Does canal clearance affect neurological outcome after thoracolumbar burst fractures. J Bone Joint Surg. 2000;85:629-635

10. ehlings MG. Recommendations regarding the use of methylprednisolone in acute spine cord injury. Spine. 2001;26:S56-S57

11. Levi AD, Casella G, Green BA, Dietrich WD, Vanni S, Jagid J, Wang MY. Clinical outcomes using modest intravascular hypothermia after acute cervical spinal cord injury. Neurosurgery. 2010;66(4):670-7

12. Kortbeek JB, Al Turki SA, Ali J, Antoine JA, Bouillon B, Brasel K, Brenneman F, Brink PR, Brohi K, Burris D, Burton RA. Advanced trauma life support, the evidence for change. Journal of Trauma and Acute Care Surgery. 2008;64(6):1638-50

13. Guo H, Wang B, Hao D. Surgical Treatment of Lower Cervical Fracture-Dislocations with Spinal Cord Injuries by Anterior Approach (5 to 15 Years Follow-up). The Spine Journal. 2015;15(10):S92

14. He A, Xie D, Cai X, Qu B, Kong Q, Xu C, Yang L, Chen X, Jia L. One-stage surgical treatment of cervical spine fracture-dislocation in patients with ankylosing spondylitis via the combined anterior-posterior approach. Medicine. 2017;96(27): e7432

15. Jiang X, Cao Y, Yao Y, Chen X, Guan J, Zhang F. Surgical management of old lower cervical dislocations with locked facet. Clinical spine surgery. 2016;29(6):E319-24 